
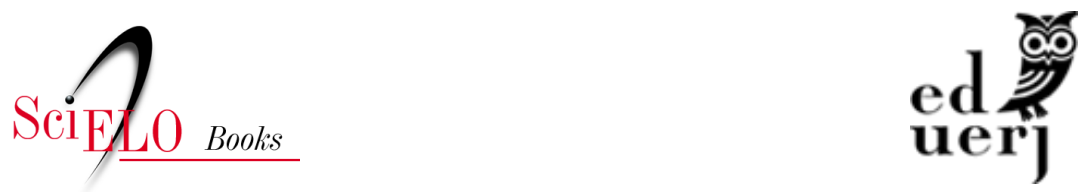

\title{
Capitulo 6 - Nas trilhas do cuidado à obesidade: quais os caminhos e os sujeitos que orientam percursos?
}

\author{
Juliana Pereira Casemiro \\ Claudia Valéria Cardim \\ Cristiane Marques Seixas
}

\section{SciELO Books / SciELO Livros / SciELO Libros}

CASEMIRO, J. P., CARDIM, C. V., and SEIXAS, C. M. Nas trilhas do cuidado à obesidade: quais os caminhos e os sujeitos que orientam percursos?. In.: SILVA, A. C. F., MOTTA, A. L. B., and CASEMIRO, J. P., eds. Alimentação e nutrição na atenção básica: reflexões cotidianas e contribuições para prática do cuidado [onine]. Rio de Janeiro: EDUERJ, 2021, pp 125-147. ISBN: 978-65-87949-11-6. https://doi.org/10.7476/9786587949116.0007.

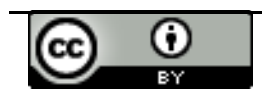

All the contents of this work, except where otherwise noted, is licensed under a Creative Commons Attribution 4.0 International license.

Todo o conteúdo deste trabalho, exceto quando houver ressalva, é publicado sob a licença Creative Commons Atribição 4.0.

Todo el contenido de esta obra, excepto donde se indique lo contrario, está bajo licencia de la licencia Creative Commons Reconocimento 4.0. 


\section{Capitulo 6 \\ Nas trilhas do cuidado à obesidade: quais os caminhos e os sujeitos que orientam percursos?}

Juliana Pereira Casemiro

Claudia Valéria Cardim

Cristiane Marques Seixas

Inicialmente, eram quatro ou cinco que apareciam com certa regularidade. Aos poucos, outras mulheres chegavam, pois a notícia de que havia um grupo de nutricionistas na comunidade foi se espalhando. Ao final de seis meses, aproximadamente setenta pessoas acima do peso reuniam-se quinzenalmente divididas em dois grupos. Pouco, a pouco um universo foi se revelando: por trás dos parâmetros de peso e altura, havia histórias de vida que se confundiam e se repetiam sem, no entanto, encontrar o devido acolhimento. Dar lugar para essas pessoas ultrapassava dar lugar para a obesidade. Tratava-se de escutar muitas queixas, acolhendo tudo que pudesse contribuir para construir uma nova forma de enfrentar o desafio cotidiano que o excesso de peso coloca aos profissionais de saúde que atuam na Atenção Básica (AB) do Sistema Único de Saúde (SUS).

O relato acima refere-se a uma das atividades desenvolvidas por professores e graduandos de nutrição no âmbito do Internato de Nutrição em Saúde Coletiva da UERJ (INSC/UERJ) que tem, entre os seus pressupostos organizadores, o compromisso da articulação entre ensino, pesquisa e extensão; a construção de processos sinérgicos e participativos de atuação a partir das diferentes realidades das Redes de Atenção à Saúde dos municípios que o acolhem; e a dedicação à formação para o SUS. Ao longo de mais de duas 
décadas, o INSC/UERJ atuou em diversos municípios do estado do Rio de Janeiro.

Tendo em vista esse percurso trilhado pelo INSC/UERJ e considerando o aumento de pesquisas e alternativas no manejo do excesso de peso, colocamo-nos algumas perguntas: por que ainda assistimos ao alarmante aumento de casos de sobrepeso e obesidade? Se a obesidade é tão presente e o problema de saúde pública é reconhecido, por que não se consegue uma abordagem eficaz? A complexidade do tratamento da obesidade pode ser contemplada pela $A B$ ? Tais perguntas apontam para interrogar potencialidades e desafios para a realização da Educação Alimentar e Nutricional (EAN) e o desenvolvimento de açóes de Promoção da Alimentação Adequada e Saudável na $\mathrm{AB}$ em articulação a um profícuo debate sobre as diretrizes de tratamento e prevenção da obesidade que vem se desenvolvendo no Brasil.

Um dos eixos norteadores para as análises apresentadas neste capítulo é a noção de acolhimento compreendida como um "que fazer", uma prática, que é vivenciada em diferentes espaços do cuidado em saúde. Em encontro aberto e receptivo entre o profissional e os usuários de um serviço de saúde, ocorre escuta respeitosa e qualificada, afetos, respostas positivas, o estabelecimento de vínculos, a ética do cuidado e o reconhecimento das necessidades e do protagonismo dos sujeitos (Franco; Bueno e Mehry, 1999; Gomes e Pinheiro, 2005; Franco, 2015; Lopes et al., 2015).

A Política Nacional de Humanização apresenta o acolhimento como uma de suas diretrizes entendendo-o como atividade construída de forma coletiva que leva em conta análises dos processos de trabalho no SUS (Brasil, 2004). Nessa perspectiva, o cotidiano é tempo-espaço em que se engendram relações de confiança, compromisso e vínculo entre as equipes, trabalhadores, serviços e destes com usuários e suas redes de apoio.

Este capítulo é dedicado a refletir sobre as experiências de um grupo educativo desenvolvido entre os anos de 2014 e 2016 a 
partir de parceria entre o INSC/UERJ, a equipe de uma Unidade Básica de Saúde e uma comunidade católica de um bairro do $3 .^{\circ}$ Distrito de Duque de Caxias. Com essa reflexão, busca-se identificar desafios, impasses, possibilidades e pistas que apresentem trilhas e caminhos para o desenvolvimento e consolidação de grupos educativos na $\mathrm{AB}$ pautados no cuidado, integralidade e promoção da autonomia. Longe de ter a pretensão de trazer algum roteiro para grupos de obesidade, a perspectiva deste capítulo é levantar questionamentos e provocar reflexóes que contribuam na construção de experiências inovadoras em diferentes contextos.

\section{Os grupos educativos e a promoção da saúde: alguns pontos de partida}

A vida em grupo é um dos elementos mais característicos do ser humano. Nascemos no seio de uma família, crescemos e nos desenvolvemos participando de diversos grupos ao longo da vida. Freud, em Psicologia das massas e análise do eu (1921), explora essa tendência do humano a se reunir no coletivo, diferenciando indivíduos e grupos sociais.

$\mathrm{Na}$ busca por desenvolver açóes pautadas na promoção da saúde, os grupos em suas diversas modalidades têm sido considerados importantes ferramentas de intervenção no contexto da $\mathrm{AB}$. Essas ações coletivas promovem uma maior participação do usuário no serviço, favorecendo a aproximação com as equipes de saúde. Os grupos são identificados no contexto do SUS como uma prática que contribui com a superação do modelo biomédico, uma vez que são concebidos como instrumentos a serviço da autonomia e do desenvolvimento contínuo do nível de saúde e condiçóes de vida (Santos et al., 2006).

A aceitação e incorporação dos grupos como prática estratégica para a promoção da saúde resulta de importante investimento, na concepção deles. Podemos considerar que há uma construção 
histórica que fundamenta o trabalho com o coletivo como área de conhecimento e atuação reconhecida no campo da psicologia. Foi o conceito de campo que abriu novos caminhos para o estudo dos grupos, especialmente para as dinâmicas de grupo. Kurt Lewin (1973) concebeu o conceito de campo psicológico como "espaço de vida" considerado dinamicamente, onde se levam em conta a totalidade dos fatos coexistentes e interdependentes.

Além de Lewin, vários teóricos dedicaram-se a pensar formas de interação e intervenção grupais, destacando-se: Moreno (1978), com o psicodrama e a teoria dos papéis; Bion (1975), que apresentou a ideia de que os grupos têm movimentos em dois planos (um consciente que objetiva a execuçáo da tarefa do grupo e outro em estado latente); Pichon-Rivière (1994), por meio de sua teoria dos vínculos e grupos operativos que tem como proposta principal que os grupos sejam centrados na tarefa, entre outros. Vale destacar que os novos paradigmas que influenciam as práticas de grupo apontam para uma ênfase na interaçáo dos membros do grupo, assim como para a falta de neutralidade na relação do coordenador do grupo e seus indivíduos que são permanentemente influenciados pelas falas de todos (Osório, 2003).

Considerando sua plasticidade conceitual e prática, pode-se conceber metodologias de grupo muito diferenciadas. Santos et al. (2006), por exemplo, apresentam uma metodologia de Grupos de Promoção da Saúde, no contexto do SUS, diferenciando-os das intervençôes por meio de grupos terapêuticos voltados para a melhoria de patologias específicas dos indivíduos (Osório, 2000); das açóes preventivistas que reduzem problemas sanitários complexos às condutas individuais de autocuidado (Castiel, 2003); e das oficinas para a promoção e cidadania, propostas por Silva (2002), na medida em que se autodefinem pela ênfase nos aspectos lúdicos dos encontros. Mais do que apresentar a vastidão de metodologias grupais, interessa-nos colocar os problemas comuns aos grupos na sua formação, seu manejo e sua continuidade, inter- 
rogando em que grau essas dificuldades e impasses têm relação com características próprias à $\mathrm{AB}$.

As experiências de trabalho com grupos educativos do INSC/ UERJ têm mostrado algumas especificidades dos usuários do SUS com excesso de peso. Em 2014, o Ministério da Saúde lançou o Caderno de Atenção Básica, de número 38 (CAB 38), dedicado às Estratégias para o Cuidado da Pessoa com Doença Crônica Obesidade (Brasil, 2014). Apesar de adotar um referencial limitado à terapia comportamental, a abordagem com grupos, delineada no $\mathrm{CAB} 38$, apresenta alguns elementos importantes. Primeiramente, indica que os grupos devem ter uma certa homogeneidade, uma vez que criam laços e permitem a exposição de sentimentos, ansiedades, medos e fantasias comuns aos participantes, gerando aproximação e empatia. Além disso, o Caderno destaca que as práticas educativas realizadas devem ter como eixos centrais a promoção de saúde e o incentivo à adoçấo de padrôes alimentares sustentáveis e que preservem a saúde, a cultura, o prazer de comer, a vida, os recursos naturais e a dignidade humana. Propóe também que os profissionais de saúde criem "trabalhos educativos que possibilitem o resgate da autoestima, a visão crítica sobre a alimentação, sobre a mídia, a propaganda de alimentos, o incentivo ao movimento, a brincadeira e a inclusão social" (Brasil, 2014, p. 105). Tais indicaçôes vão ao encontro dos princípios da EAN previstos no Marco de Referência de Educação Alimentar e Nutricional para as Políticas Públicas (Brasil, 2012), que reafirma a humanização e o cuidado como diretrizes a serem construídas no âmbito do SUS.

À medida que cresce entre os profissionais de saúde a consciência de que ouvir os sujeitos do cuidado é um desafio essencial no aprimoramento da atenção à saúde, percebe-se a ampliação de possibilidades de construção de novas estratégias ao mesmo tempo que se constata a necessidade de muitas mudanças no que diz respeito à organização dos serviços, à postura dos profissionais e à própria formaçáo de trabalhadores da saúde. 
Para Canesqui (2015, p. 13), esta necessidade de "ouvir os adoecidos" está relacionada à prerrogativa de que estes não são sujeitos passivos que, submetidos às técnicas e intervençóes, automaticamente correspondem ao desejo profissional de "adesão, colaboração e submissão às prescrições e tratamento biomédico". Nesse caminho, ressalta a compreensão dos saberes e modos de reflexão sobre o corpo, saúde, doença e cuidado como importantes constituintes da atenção à saúde, de modo a contribuir para adequação das ações à realidade sociocultural e singularidades do entorno em que estão inseridos os sujeitos. É importante, nessa direção, promover aproximação com a vida, narrativas, representaçóes e experiências de diferentes grupos sociais.

Ainda segundo Canesqui (2015), essa constatação não chega a ser novidade, uma vez que debates sobre integralidade e humanização têm promovido reflexóes sobre "resgatar a pessoa" para o centro da organização de açóes em saúde. Então, por que ainda é tão difícil assumir e lidar com esses desafios? A hegemonia da medicina e "suas instituiçôes, poder, saber e práticas" constituem uma importante barreira, mas não é a única.

A atuação do INSC/UERJ tem permitido identificar que a organização dos serviços de saúde, ordenada por uma crescente busca da eficiência no cumprimento de metas de atendimento e cobertura, impacta nas possibilidades de dedicar tempo à fundamental tarefa do diagnóstico da realidade, da construção de entendimentos sobre o território e da compreensão sobre as comunidades e os sujeitos em suas particularidades e subjetividades. Este possivelmente é um elemento que tem efeitos na demanda cotidiana dos serviços por manuais ou receitas que garantam o sucesso nas intervençóes. Mas será que essa garantia é possível?

Pensando do ponto de vista das atividades educativas, é necessário destacar que materiais recentes do Ministério da Saúde apontam, tanto em termos de Educação em Saúde (Brasil, 2016) quanto de EAN (Brasil, 2012), a necessidade de incorporaçóes das 
referências da educação crítica e da pedagogia problematizadora. Essas perspectivas são compatíveis ao entendimento necessário de que a simples reprodução de práticas exitosas em determinado contexto ou dirigidas a determinado grupo não garante sucesso em outro espaço-tempo de atuação.

São as classes populares as que mais procuram e acessam a AB. O olhar mais apressado sobre o cotidiano pode, portanto, partir de um pressuposto de que as pressóes vivenciadas por essa população são semelhantes e, por isso, tendem a ser vistas de forma padronizada ou simplificada. Contudo, cabe destacar que tanto as experiências anteriores de cada pessoa quanto o contexto atual em que vivem impactam de forma diversa as maneiras de experimentar, significar e reagir ao sofrimento. Nas palavras de Canesqui (2015, p. 17): “a experiência com a enfermidade é singular, mas também social e historicamente situada”. É nesse sentido que a autora afirma que se convive ou se rejeita o sofrimento, assim como existe a possibilidade de reorganização ou manutenção de rotinas e da própria vida, e todas essas possibilidades estão relacionadas com as singulares formas de experimentar o adoecimento.

Algumas pistas podem ajudar a identificar um adequado ponto de partida para caminhos mais dialógicos e acolhedores: é importante lembrar que a vida acontece e floresce em grupo. É necessário valorizar a escuta atenta das vozes, das falas interditadas e do silêncio dos sujeitos com os quais se pretende dialogar, e é imprescindível sentir o chão em que se pisa enquanto se mira a estrada a ser percorrida com o grupo para que nossos olhos permaneçam atentos, sensíveis e críticos.

\section{Algumas pedras do caminho: o sofrimento das tentativas de emagrecer}

$\mathrm{Na}$ efetivação do grupo educativo e na convivência com os serviços de saúde, estudantes e professoras do INSC/UERJ encon- 
traram grande incômodo ao perceberem certa "invisibilidade" da pessoa com obesidade na $\mathrm{AB}$, contrastando assim com o reconhecimento de altas prevalências de excesso de peso e de sua associação com as principais causas de adoecimento na população adulta (Bahia e Araújo, 2014; Schieri et al., 2007). Impactou o fato de que grande parte dos usuários procurava os serviços de saúde com queixas secundárias ao excesso de peso (hipertensão, diabetes, dores articulares, entre outras) e que, via de regra, nem esses sujeitos e nem os profissionais que os atendiam colocavam a ênfase no peso corporal, e, quando o faziam, partiam de pressupostos recriminatórios e preconceituosos.

A experiência foi mostrando que, ao final, tais atitudes resultam em recusa em frequentar os serviços de saúde para onde deveriam prioritariamente direcionar suas demandas de saúde. No cotidiano, são vários os exemplos dessa rejeição: mulheres com obesidade que deixam de fazer seu preventivo anual; adolescentes e jovens que evitam atendimento de saúde até mesmo para simples vacinaçáo; ou idosos com doenças crônicas que acabam frequentando os serviços apenas para "atualização de receitas médicas", todos com receio de julgamento sobre seu peso.

O processo saúde/doença e o próprio corpo são parte de um sistema complexo de dimensões que inclui não apenas o biológico, mas também o cultural, o histórico e o social. A visão sobre o corpo e as intervençóes de saúde propostas acercam-se de indissociável relação de poder, sendo a ideia de obesidade como doença um complexo pot-pourri de hipóteses científicas, morais e ideológicas sobre as pessoas e suas vidas, com efeitos éticos questionáveis (Seixas e Birman, 2012).

Apesar das muitas controvérsias, a obesidade foi incluída há algumas décadas na Classificação Internacional de Doenças (CID). O tamanho dos corpos passa a ser objeto de observação dos médicos (e de outros profissionais de saúde), e o corpo gordo passa a ser identificado como um desvio da normalidade na sociedade contem- 
porânea, ficando sob vigilância e controle constantes. A percepção médica sobre a obesidade é reducionista porque considera apenas uma referência: a da própria medicina (Yoshino, 2013). O mesmo pode ser afirmado da visão de outros profissionais de saúde que, em geral, excluem o olhar e a percepção do sujeito do cuidado.

Nesse sentido, as prescriçóes de dieta, regime ou reeducaçáo alimentar somados ao uso de medicamentos e uma infinidade de tratamentos, incluindo os cirúrgicos, prometem respostas rápidas e eficazes na perda de peso. A "indústria do emagrecimento" torna-se maior e mais poderosa a cada dia (Yoshino, 2013). De que forma esse cardápio de promessas e a coleção de tentativas de emagrecimento interferem e impactam o trabalho desenvolvido no atendimento individual e na manutenção de grupos?

As análises sobre atividades do INSC/UERJ revelam que esta é uma questão central para o acolhimento de participantes de grupo. Certa vez, uma mulher, com cerca de trinta anos de idade, foi encaminhada pela médica para participar do grupo. Foi convidada a apresentar-se e revelou que desde o nascimento de seu primeiro filho estava encontrando dificuldade para emagrecer. Apressou-se em informar que trabalhava como cozinheira e costumava preparar salada para seu próprio almoço, mas tinha dificuldade de manter o horário de refeições e, ao chegar em casa, não tinha disposição para cozinhar. Conseguiu emagrecer quando, junto com a irmã, frequentou um médico considerado por ela muito bom, mas muito caro.

As duas voltaram a ganhar peso, e, naquele momento, a sua irmã estava na fila da cirurgia bariátrica porque tinha plano de saúde. Ela afirmou que a obesidade era um problema que afligia grande parte da família e que só estava no grupo porque não tinha condições financeiras de fazer a cirurgia bariátrica, além de alegar que no SUS a fila é muito grande. Seu histórico no grupo foi curto: foi à primeira reunião, apresentou sua trajetória de tentativas de perder peso, confessou sua descrença em novos tratamentos, sentiu-se acolhida, 


\section{Alimentação e nutrição na Atenção Básica}

prometeu voltar, mas não retornou. Essa experiência assemelha-se a tantas outras que se dão cotidianamente no trabalho com grupos de de pessoas com obesidade, sendo a adesão ao tratamento um problema complexo, como apontam Estrela et al. (2017).

Quando se vivencia uma história como essa, pelo menos duas reaçóes são possíveis entre profissionais e estudantes. Primeiro, tende-se a pensar que aquele era mesmo um caso difícil ou perdido, já que, provavelmente, faltaria "força de vontade" para mudar seus hábitos. Em segundo lugar, profissionais e estudantes tendem a culpar-se fazendo a clássica pergunta: onde foi que eu errei?

Esses aspectos podem refletir em parte o que alguns autores tendem a denominar de "inércia clínica". Esse termo, usado para discutir o insucesso no tratamento de doenças crônicas, embora enfatize abordagens acerca da efetividade de protocolos terapêuticos, tangencia alguns debates em relação às limitações na formação e capacitaçáo dos profissionais de saúde no manejo de doenças multicausais, como, por exemplo, diabetes e hipertensão arterial. Nessa dinâmica, o profissional assume uma espécie de conformidade, ou impotência, frente à não evolução do paciente ou sua piora, ou mesmo desconsidera aspectos importantes no curso do tratamento, seja na inadequação do plano terapêutico, ou nos elementos individuais ou contextuais que dificultam a adesão do usuário e consequente fracasso no controle da doença (Phillips e Twombly, 2008; Hoepfner e Franco, 2010).

Com base nas experiências vivenciadas no INSC/UERJ, essa chamada "inércia clínica" pôde ser compreendida nas histórias das buscas de tratamento relatadas pelas participantes dos grupos e nas conversas com diferentes profissionais dos serviços de saúde, na medida em que uma crença é reforçada de que a pessoa com obesidade na verdade "não quer realmente se tratar", ou mesmo na sensação de incapacidade do profissional em "resolver" o problema. 


\section{Direçáo compartilhada: em busca da trilha possível}

Compartilhar com um grupo suas histórias de vida e muitas vezes de fracassos é uma tarefa difícil para grande parte das pessoas, uma vez que são marcadas pela crítica constante, impedindo-as de assumir suas falhas, que são, em última análise, próprias do ser humano e precisam ser admitidas e reconhecidas como parte do caminho. Firma-se, nesse sentido, a necessidade de desculpabilizar os espaços de cuidado, tendo em vista que o crescente processo de medicalização da obesidade (Seixas e Lucena, 2016; Figueiredo, 2009) tem como efeito a disseminaçáo de certos julgamentos e críticas ao paciente, assim como ao profissional de saúde que náo consegue levar a cabo a cura da doença. Por estarem imersas nessa cultura que entende a obesidade como uma escolha individual, associada à preguiça e à falta de força de vontade de cada um, as equipes de saúde apresentam um padráo de comportamento similar ao da população geral (Francisco e Diez-Garcia, 2015), ou seja, respondem, por um lado, à imposição de cura de uma doença (obesidade), mas esbarram em dificuldades que ultrapassam o seu campo fisiológico, sendo, então, os profissionais responsabilizados também pelo insucesso.

Cabe lembrar que a obesidade na contemporaneidade "estigmatiza o sujeito e forja-lhe uma identidade" (Yoshino, 2013, p. 17). Nesse sentido, manter um corpo gordo pode gerar uma série de experiências traumáticas e constrangedoras, como, por exemplo, não conseguir usar transporte coletivo por causa das roletas, não ter cadeiras adequadas para sentar-se, não ter a pressão arterial aferida em unidades de saúde por falta de aparelho apropriado, náo encontrar roupa adequada para comprar, sem contar com a falta de autonomia para tarefas simples, como amarrar os sapatos ou cortar as próprias unhas dos pés.

O histórico de insucesso, tentativas e fracassos de pessoas que convivem com o excesso de peso impacta na forma de participação 
e mobilização de esforços para vincular-se às atividades em grupo. Muitos chegam aos grupos após uma longa jornada de frustrações que tem como provável consequência a descrença e desesperança nas possibilidades de efetiva mudança. Nesse sentido, destaca-se uma lacuna de conhecimento relacionada à escassez de estudos dedicados a analisar o porquê de recaídas ou de ganho de peso gradual após intervençóes (Yoshino, 2013).

Ao colocar no centro das açóes de saúde a perda de peso como principal indicador de sucesso, encontram-se argumentos que sustentam o processo de medicalização da obesidade. Justifica-se, assim, a ampliação da oferta de novos medicamentos e das cirurgias bariátricas que aparecem como tábua de salvação, como opção rápida e capaz de aliviar de forma "efetiva" a convivência crônica com uma série de sofrimentos.

Essa contradição pode ser observada até mesmo nos materiais recentemente produzidos pelo Ministério da Saúde que orientam as práticas dos profissionais em relação ao excesso de peso e obesidade. O CAB 38 (Brasil, 2014) indica que o horizonte de sucesso do tratamento seria perda do peso propriamente dita, enquanto o Guia Alimentar para a População Brasileira (Brasil, 2015) e o Marco de Referência de Educação Alimentar e Nutricional para as Políticas Públicas (Brasil, 2014) valorizam a promoção da alimentação adequada e saudável, assim como a mudança de hábitos relacionados ao consumo de ultraprocessados. Que outros parâmetros poderiam contribuir para medir o sucesso do cuidado em obesidade?

As experiências vividas no INSC/UERJ têm demonstrado que existe a necessidade de criar outras formas de avaliar o grupo e apresentar outros indicadores que não sejam exclusivamente a perda de peso e outras medidas corporais. Embora tais medidas sejam úteis do ponto de vista do acompanhamento clínico e sejam clássicas na perspectiva dos estudos epidemiológicos, nas análises e avaliaçôes sobre grupos, elas se tornam no mínimo insuficientes. Pode-se assinalar que, ao longo de anos de trabalho com grupos 
de usuários com excesso de peso, foram observados ganhos significativos em relação à qualidade de vida, tais como: a aquisiçáo de novas habilidades culinárias, a maior disposição para atividades diárias, a incorporaçáo de atividade física regular, a melhoria na qualidade dos alimentos ofertados a crianças e demais membros da família, a organizaçáo de horários de refeiçôes, a diminuição de crises compulsivas e até mesmo a melhora de quadros depressivos, a diminuição dos níveis de glicemia, tensoriais e a busca por novos caminhos na vida, como voltar a estudar e trabalhar. Como tomar esses ganhos como parâmetros de melhora da saúde e diminuição de queixas subjacentes?

Existe uma questáo importante relacionada ao isolamento, muitas vezes associado à obesidade, que, no contexto grupal, pode ser contornada. Situaçôes concretas como o medo da censura, ou a simples falta de disposição, fazem parte de uma lista de limites para participação em atividades de lazer. Assim, o primeiro ganho do grupo é o convívio e a possibilidade de partilhar experiências, dores e sofrimentos sem o medo da reprovação. Encontrar formas de superação de impasses de maneira coletiva aparece também como um elemento importante. Criar um clima apropriado para acolher dificuldades e "deslizes" relacionados à incorporação de novos hábitos é fundamental para o estabelecimento de relação de confiança que permita fortalecer a noção de pertencimento e as relaçốes de mútuo apoio que ultrapassam o horário do grupo.

Assim, do ponto de vista da experiência concreta com grupos, podemos considerar como um bom indicador de sucesso em termos de organizaçáo de percursos o nosso "inacabamento", compreendendo que profissionais e usuários aprendem a cada novo encontro. Aprendem não somente com o que lhe é ensinado por alguém que sabe, mas também pelo encontro com as diferenças e as falhas de todos que se propóem a, de fato, participar de um grupo. Parte também de uma esperança na transformação que só é possível no reconhecimento que somos todos seres condicionados 
e não determinados (Freire, 2005). É isso o que abre espaço para a mudança e para a construção do novo.

A avaliação compartilhada das atividades é integrante de toda prática educativa crítica e comprometida com a transformação. Nos grupos, essa avaliação deve partir do planejamento realizado pelo profissional responsável por facilitar o diálogo entre os participantes, mas deve considerar as necessidades, o ponto de partida e a realidade dos sujeitos envolvidos no processo, o que inclui os usuários e outros profissionais do serviço envolvidos na ação. Há, portanto, uma condução compartilhada das atividades, o que pode se chamar de uma "atividade bem-sucedida" que precisa ser pactuada pelo grupo, sempre lembrando que nossas experiências são histórica e socialmente marcadas pelo contexto, pelo território e outros aspectos da vida em sociedade.

Outro parâmetro classicamente utilizado para avaliar o sucesso de um grupo é medir a continuidade de participação. Quando não há a adesão esperada, nos perguntamos se o grupo funcionou, ou o que faltou para que os participantes aderissem à proposta. Sabe-se que um dos maiores desafios no tratamento da obesidade é a adesão e a continuidade, o que nos faz pensar que as propostas de grupo mais estruturadas dificultam que outros parâmetros de sucesso sejam considerados. Em relação à frequência e periodicidade, nossa experiência no INSC/UERJ mostrou que os efeitos de participar de experiências de EAN não se limitam unicamente ao sujeito do cuidado, podendo ser compartilhada com familiares, amigos, vizinhos e redes de convivência, levando para cada vez mais pessoas as informaçóes e o conhecimento construído em grupo.

É apostando nessa capacidade de disseminação intrínseca à educação popular em saúde que pudemos entender que as idas e vindas de alguns participantes, as apariçóes pontuais, às vezes para pegar material ou somente para se pesar, deveriam ser consideradas como índices de sucesso do grupo, e não de insucesso. Êxito, nesse sentido, é saber que a presença de profissionais na $A B$, oferecendo 
um espaço onde não há cobranças e exigências, possibilitou a busca por um acompanhamento, ainda que não no formato indicado pelos protocolos de prevenção e tratamento da obesidade.

\section{Qual o lugar da comida no grupo?}

Apesar do estranhamento de muitos profissionais, nas atividades do INSC/UERJ as trocas de receitas passaram a ser parte integrante dos encontros do grupo relacionado à perda de peso. Em grande parte das situaçôes, a motivação por mudanças de hábitos alimentares foi associada à rotina de troca de receitas saudáveis que passava a ocorrer também de forma espontânea entre as participantes, incluindo intercâmbio de ingredientes - mudas de hortelá e boldo, folhas de chaya, limão, pimenta, entre outros temperos.

A percepção de que atividades de EAN precisam incorporar elementos lúdicos e encontrar caminhos para conectar saberes da nutrição aos aspectos cotidianos da alimentação tem sido afirmada em outras experiências (Casemiro et al., 2015; Recine et al., 2016). Além disso, parte-se da premissa de que a construção compartilhada de conhecimento incorpora saberes oriundos das esferas de vida dos participantes em articulação com o conhecimento científico e as experiências dos facilitadores de modo horizontal, e não hierárquico. Dentre os espaços e temas exitosos para tal conexão, destaca-se o espaço da comensalidade e da culinária como campo fértil de atuação. Talvez pareça um contrassenso trazer a comida para o centro de uma atividade de grupo com pessoas em sobrepeso e obesidade. No entanto, é importante insistir: se os sentidos do comer se dão no mundo da vida (Freitas e Santos, 2014) e se os excessos alimentares são identificados como fator importante no desenvolvimento da obesidade, como náo refletir sobre o lugar da comida no cuidado, dando a ela o espaço na prática que lhe é devido?

Uma das experiências interessantes do grupo foi uma oficina culinária de elaboraçáo criativa de pastas de ricota. As participantes 
puderam contribuir trazendo ingredientes e elaborando receitas próprias para degustação. Curiosamente, uma das participantes se recusava a experimentar, insistindo que não gostava de ricota, mas em função do diálogo e do questionamento sobre o que ela perderia em provar uma ou duas pastinhas ela aceitou experimentar. Surpreendentemente, gostou muito e passou a incorporar na sua dieta tal proposta. No aprendizado coletivo dessa atividade, destaca-se sua capacidade de proporcionar a abertura de novas práticas alimentares em grupo, assim como a integração e alegria com que os participantes se envolvem com a comida. Diante dessas e outras experiências, nos perguntamos: podemos considerar a simples incorporação de novos alimentos e preparaçóes na dieta cotidiana por alguns participantes como um indicador de sucesso?

Freitas e Santos (2014) ressaltam a importância de que refletir sobre o sentir (ou não) prazer ao comer é relevante para compreender o fenômeno da nutrição, ressaltando que a comida prazerosa nem sempre produz alegrias, e destaca a obesidade como um exemplo. $\mathrm{O}$ desejo de consumir o que se coloca à disposição no mercado é questão chave nesse processo. À venda, estão "produtos que são coisas do desejo de comer, apoiando-se em uma subjetividade do prazer” (p. 34). Quando a ação terapêutica sobre a obesidade se concentra na negação da comida e do prazer que ela proporciona, fecham-se possibilidades de dialogar sobre como cada um é capaz de conciliar com a sua vida hábitos capazes de promover qualidade de vida, saúde e felicidade. A ideia popular de que o que é bom "é ilegal, é imoral ou engorda" ainda é um ranço que amarra as possibilidades de pensar novas relaçóes com a alimentação e nutrição.

Nesse sentido, outra experiência que merece registro teve como título "Como alimentar as emoçóes?", cujo foco principal foi a ansiedade, queixa bastante comum entre os membros do grupo. Foi elaborado um quadro onde as participantes diziam: "o que eu como quando: 1) estou triste? 2) estou feliz? 3) estou com fome?”. Percebemos que a maioria das participantes, quando perguntadas o 
que elas comem quando estão tristes ou felizes, responderam doces, massas, refrigerantes, produtos industrializados. Quando questionadas sobre o que comem quando estão com fome, responderam basicamente a comida de hábito cotidiano do brasileiro, como: feijão, arroz, carne e legumes. Alimentos, como balas, sorvetes, salgadinhos foram referidos em situaçôes de tristeza e ansiedade. Isso levou a uma análise interessante dos sentimentos que são atribuídos à comida e a relação com o que se come. Quando estamos com fome, queremos a comida do dia a dia que nos alimenta e alivia a sensação de fome, mas quando estamos em algum estado mais sentimental, precisamos nos recompensar com algo diferente, gerando a falsa sensação de alívio. A partir desse momento lúdico, foi possível desdobrar alternativas para enfrentar cada emoção destacada, pois cada participante em sua singularidade trouxe, para o contexto grupal, como lidava com situaçóes que eram comuns a todos.

O comer, que na sociedade contemporânea ganhou novos contornos e conotaçóes, coloca novas demandas reflexivas para preparar a atuação no campo da Alimentação e Nutrição. Nas palavras de Barbosa (2016, p. 95):

O que comemos é hoje, em grande parte, objeto daquilo sobre o que falamos, o que assistimos, lemos, discutimos, militamos politicamente, combatemos, curtimos, defendemos, regulamos e com o que nos identificamos.

O Guia Alimentar para a População Brasileira (Brasil, 2015) traz reflexóes que nos aproximam dessa complexidade. Reconhece, por exemplo, que um dos grandes desafios da Promoção da Alimentação Adequada e Saudável não é a escassez de informação, mas, sim, o seu contrário. Existe hoje um excesso de informações disponíveis sobre os temas de alimentação e nutrição, e a grande dificuldade, para profissionais e para a população em geral, é a identificação de quais são as informações seguras. 
Novos preconceitos e tabus alimentares são criados a cada instante e com um agravamento: as redes sociais, que formam papel importante na rapidez da disseminação de modas e modos. Dessa forma, a "dieta sem" - sem glúten, sem lactose, sem carboidrato - ou os novos sentidos do jejum - que não é mais religioso, é intermitente - são questóes possivelmente acessadas por frequentadores dos grupos e que irão exigir constante atualização caso se aposte na contraposição dos modismos. É fato que estes sempre existiram, mas seus ciclos costumavam ser mais duradouros, uma vez que os mecanismos de disseminação da informação apresentavam contornos diversos ao do atual mundo conectado por uma variedade de fontes e redes sociais, o que permitia tempo maior para apropriação do que está na moda.

Colocar a comida no centro dos debates dos grupos tem oportunizado o resgate das histórias alimentares do ponto de vista individual, familiar e comunitário. Partir desse exercício para enxergar mudanças e permanências alimentares tem contribuído na tarefa de problematizar as escolhas e práticas alimentares.

A identificação realizada pelos sujeitos sobre o aumento do consumo pessoal e familiar de ultraprocessados, muitas vezes em substituição a preparaçóes e hábitos que faziam parte da infância ou que estão associados a fatores culturais, é relevante. Identificar pode, em muitas situações, influenciar mudanças, mas pode também causar paralisias. A constatação de que produtos alimentares ultraprocessados são as opçóes prazerosas e, por vezes, mais baratas, bem como a ideia de praticidade e o status a eles relacionados, circunscreve toda uma coleção de produtos alimentares num imaginário próprio. Coloca-se um desafio central aos sujeitos no que diz respeito ao seu autocuidado alimentar: como substituir tais alimentos que estão presentes cotidianamente em suas casas?

Ampliar as habilidades culinárias e os repertórios alimentares constitui papel importante nesse caminho. Retornamos então à afirmação de que o estímulo à troca de receitas representa estratégia 
relevante ao encorajar o hábito de cozinhar, ao estimular a troca de saberes e ao contribuir na criação de vínculo entre os participantes do grupo. Entretanto, considerar e discutir os mecanismos complexos que envolvem pensar no que comer e ter o alimento ou refeição prontos para o consumo é algo fundamental a ser considerado na pauta desse debate.

\section{Consideraçóes finais}

Assumir o acolhimento como uma categoria central na organização do cuidado significa mais uma vez priorizar a integralidade, equidade e universalização como pilares fundantes do SUS, mas não só. É preciso avançar na reflexão das estratégias que colocam em prática tais princípios, fazendo-os extrapolar o contexto das políticas públicas, inserindo-os nas políticas da vida. Os sentidos atribuídos aos temas da integralidade-vínculo-acolhimento impactam de forma decisiva na organização de serviços e relacionam-se com as possibilidades de expressão de saberes e reafirmação de culturas, criando possibilidades que têm efeitos no acesso, inclusão, participação e direito à saúde (Gomes e Pinheiro, 2005). Essa perspectiva alia o entendimento da recíproca influência entre construção do acolhimento e os aspectos relacionados aos processos de trabalho ao da organização de serviços (Franco, 2015), assim como contribui para a construçáo coletiva e cotidiana de um novo olhar sobre o excesso de peso que garanta a consideraçáo de outros parâmetros para a avaliação de seu tratamento. A organização de grupos na $\mathrm{AB}$ aciona conhecimentos e recursos decisivos para esse caminho.

Os grupos educativos pautados pelos princípios referidos no Marco de Referência de Educação Alimentar e Nutricional para Políticas Públicas (Brasil, 2012) são capazes de contribuir para escolhas alimentares saudáveis e ampliação de redes de apoio social. Isso impacta na qualidade de vida, na medida em que proporcionam o resgate da comensalidade, do prazer, da empatia por meio 
da integração do indivíduo com seu corpo, suas emoções e com o meio onde vive e se relaciona, e náo somente sua tentativa de controle e recusa.

As questôes suscitadas pelas experiências do INSC/UERJ apontam os paradoxos que se impóem ao tomar a obesidade como doença, uma vez que não pode ser tratada exclusivamente pelo dispositivo médico, o que nos leva a recusar a simplicidade dessa problemática. Trata-se de enfrentar o desafio que a complexidade da obesidade coloca, sem admitir que quimeras medicamentosas e comportamentais ocupem espaço privilegiado nas propostas de tratamento e prevenção.

Esse desafio está mais do que colocado no cotidiano da AB: indivíduos com excesso de peso em busca de um caminho rápido para lidar com seu corpo e sua compulsão, ao mesmo tempo que esperam um acolhimento para as dificuldades, que não são poucas. O que se observa numa experiência que se abre ao "inacabamento" é que, ainda que não se tenha garantias, o acolhimento desses sujeitos proporciona um lugar para localizar e direcionar a queixa que muitas vezes é recusada nos itinerários das equipes de saúde, o que por si só tem um efeito de reconhecimento, e não um silenciamento que só faz dificultar ainda mais o processo.

A percepção de que é preciso livrar-se de preconceitos e do excesso de expectativas e aceitar que existem tempos diferentes para as mudanças de vida de cada indivíduo são fundamentais para o exercício de uma prática crítica e problematizadora. $\mathrm{O}$ que se fala em grupo é considerado importante e único, permitindo-nos afirmar que náo se replicam experiências, mas elas servem de base e inspiração para outras iniciativas que ousem sair de um lugar garantido nas políticas e nos manuais. Um grupo de perda de peso não é apenas um grupo para perder peso onde se verificam números e estatísticas: é importante oferecer espaço de fala, exercitar a escuta e o acolhimento para, quem sabe, encontrar caminhos e trilhas alternativos que incluam o sujeito e seu sofrimento. 


\section{Referências}

BAHIA, L. R. e ARAÚJO, D. V. "Impacto econômico da obesidade no Brasil". Revista Hospital Universitário Pedro Ernesto, v. 13, n. 1, pp. 13-7, Rio de Janeiro, 2014.

BARBOSA, L. "A ética e a estética na Alimentação Contemporânea”. In CRUZ, F. T. et al. Produção, consumo e abastecimento de alimentos: desafios e novas estratégias. Porto Alegre: Editora da UFRGS, 2016.

BION, W. R. Experiências com grupos: fundamentos da psicoterapia de grupo. Rio de Janeiro: Imago; São Paulo: EDUSP, 1975.

BRASIL. Ministério da Saúde. Secretaria-Executiva. Núcleo Técnico da Política Nacional de Humanização. Humaniza SUS: Política Nacional de Humanização: a humanização como eixo norteador das práticas de atenção e gestão em todas as instâncias do SUS. Brasília: Ministério da Saúde, 2004.

. Ministério do Desenvolvimento Social e Combate à Fome. Marco de referência de educação alimentar e nutricional para as políticas públicas. Brasília, DF: MDS, 2012.

. Ministério da Saúde. Secretaria de Atenção à Saúde. Departamento de $\mathrm{AB}$. Estratégias para o cuidado da pessoa com doença crônica: obesidade. Brasília: Ministério da Saúde, 2014.

. Ministério da Saúde. Secretaria de Atenção à Saúde. Departamento de AB. Guia alimentar para a população brasileira: relatório final da consulta pública [recurso eletrônico]. Brasília: Ministério da Saúde, 2015.

. Ministério da Saúde. Universidade Federal de Minas Gerais. Instrutivo: metodologia de trabalho em grupos para açóes de alimentação e nutrição na Atenção Básica. Brasília: Ministério da Saúde, 2016

CANESQUI, A. M. "Pressão alta" no cotidiano: representaçóes e experiências. Rio de Janeiro: Editora Fiocruz, 2015.

CASEMIRO, J. C. et al. "Impasses, desafios e as interfaces da educação alimentar e nutricional como processo de participação popular”. Trab. Educ. Saúde, v. 13 n. 2, pp. 493-514, Rio de Janeiro, 2015

CASTIEL, L. D. "Dédalo e Dédalos: identidade cultural, subjetividade e os riscos à saúde”. In CZERESNIA, D. e FREITAS, C. M. (orgs.). Promoçâa da saúde: conceitos, reflexóes e tendências. Rio de Janeiro: Fiocruz; 2003, pp. 79-95.

ESTRELA, K. C. A. et al. "Adesão às orientaçôes nutricionais: uma revisão de literatura”. DEMETRA: Alimentação, Nutrição \& Saúde, v. 12, n. 1, pp. 249-74, fev. 2017. 
FRANCISCO, L. V. e DIEZ-GARCIA, R. W. "Abordagem terapêutica da obesidade: entre conceitos e preconceitos". DEMETRA: Alimentação, Nutrição \& Saúde, v. 10, n. 3, pp. 705-16, Rio de Janeiro, 2015.

FRANCO, T. B. et al. "O acolhimento e os processos de trabalho em saúde: o caso de Betim, Minas Gerais, Brasil”. Cad. Saúde Pública, v. 15, n. 2, pp. 345-53, 1999.

"Redes de Cuidado: conexão e fluxos para o bom encontro com a saúde". In ALMEIDA, P.F. et al. Atenção primaria à saúde na coordenaçâo do cuidado em regióes de saúde. Salvados: EdUFBA, 2015.

FREITAS, M. C. S. e SANTOS, L. A. S. "Sobre a fenomenologia de comer saudável no mundo da vida - breve ensaio". In FREITAS, M. C. S. e SILVA, D. O. Narrativas sobre o comer no mundo da vida. Salvador: EdUFBA, 2014. FREIRE, P. Pedagogia do Oprimido. Rio de Janeiro: Paz e Terra, 2005.

FREUD, S. "Psicologia das massas e análise do eu". In - Psicologia das massas e análise do eu e outros textos. São Paulo: Companhia da Letras, 2011 [1921]. GOMES, M. C. P. A e PINHEIRO, R. "Acolhimento e vínculo: práticas de integralidade na gestáo do cuidado em saúde em grandes centros urbanos". Interface - Comunic., Saúde, Educ., v. 9, n. 17, pp. 287-301, 2005.

HOEPFNER, C. e FRANCO, S. C. "Inércia clínica e controle da hipertensão arterial nas unidades de atenção primária à saúde”. Arq. bras. Cardiol., v. 95, n. 2, pp. 223-9, 2010.

LEWIN, K. Princípios de Psicologia topológica. São Paulo: Cultrix/USP, 1973.

LOPES, A. S. et al. "O acolhimento na Atenção Básica em saúde: relaçôes de reciprocidade entre trabalhadores e usuários”. Saúde Debate, v. 39, n. 104, pp. 114-23, 2015.

MORENO, J. L. Psicodrama. 2 ed. São Paulo: Cultrix, 1978.

OSÓRIO, L. C. Psicologia Grupal: uma nova disciplina para o advento de uma nova era. Porto Alegre: Artmed, 2003.

. Grupos: teorias e práticas acessando a era da grupalidade. Porto Alegre: Artmed, 2000.

PHILLIPS, L. S e TWOMBLY, J. G. "It's time to overcome clinical inertia". Ann Intern Med, v. 148, n. 10, pp. 783-5, may 2008.

PICHON-RIVIÈRE, E. O processo grupal. 5 ed. São Paulo: Martins Fontes, 1994.

RECINE, E. et al. Mulheres do Recanto: antes de saber o que eu como, deixa eu contar como eu vivo. Brasília: Observatório de Políticas de Segurança Alimentar e Nutrição, Universidade de Brasília, 2016.

SANTOS, L. M. et al. "Grupos de promoção à saúde no desenvolvimento da autonomia, condiçốes de vida e saúde". Revista de Saúde Pública, v. 40, n. 2, pp. 346-52, [s. 1.], 2006. 
SEIXAS, C. M. e BIRMAN, J. "O peso do patológico: biopolítica e vida nua”. Hist. cienc. saúde-Manguinhos, v. 19, n. 1, pp. 13-26, Rio de Janeiro, mar. 2012.

e LUCENA, B. B. "O mundo não é um Spa: sobre a ética do desejo na clínica da obesidade”. In PRADO, S. et al. Estudos socioculturais em alimentação e saúde: saberes em rede. Rio de Janeiro: EdUERJ, 2016.

YOSHINO, N. L. "As representaçóes e experiências de adultos com o corpo obeso". In CANESQUI, A. M. "Adoecimento de longa duração". São Paulo: Hucitec, 2013. 